\title{
Amenazas biológicas intencionadas: implicaciones para la Seguridad Nacional*
}

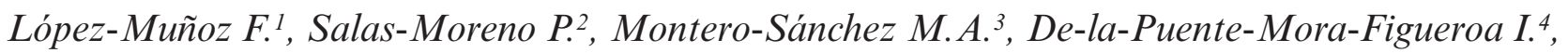 \\ Suárez-Muñoz A. ${ }^{5}$, García-Crespín J.F. ${ }^{6}$,Díaz-Muñoz, $F^{7}$
}

Sanid. mil. 2021; 77 (2): 98-105, ISSN: 1887-8571

\begin{abstract}
RESUMEN
El uso de material biológico como arma de guerra es tan antiguo como los propios conflictos bélicos, pero tras la firma, en 1972, de la Convención sobre la prohibición del desarrollo, la producción y el almacenamiento de armas bacteriológicas (biológicas) y toxínicas y su destrucción (CABT), su uso militar prácticamente ha desaparecido. Sin embargo, ha pasado a formar parte de los ataques de grupos terroristas, que constituyen una auténtica amenaza para la Seguridad Nacional. Las armas biológicas se incluyen dentro del grupo de las denominadas "armas de destrucción masiva" e incluyen a todo tipo de agentes, microbianos o no, virales, naturales o recombinantes, y a sus toxinas derivadas. Entre los factores claves en el desarrollo de este tipo de amenazas biológicas intencionadas, cabe mencionar el incremento de la aparición de patógenos emergentes, el gran desarrollo de las tecnologías de modificación y edición genética, como la CRISPR/Cas9, o el desvío y contrabando de precursores y materiales sensibles. El principal desafío al que se enfrenta la Seguridad Nacional ante este tipo de amenazas es su identificación y detección precoz. Para ello, se han implementado las siguientes medidas: puesta en marcha de la Comisión Nacional de Biocustodia; control de las exportaciones de material de doble uso; potenciación del Área de Seguridad y Protección del Departamento de Aduanas e Impuestos Especiales de la Agencia Tributaria; desarrollo de la Red de Laboratorios de Alerta Biológica (RE-LAB), coordinada por el Instituto de Salud Carlos III; colaboración de los Equipos Técnicos Españoles de Ayuda y Respuesta en Emergencias (START).
\end{abstract}

PALABRAS CLAVE: Amenazas biológicas, armas biológicas, virus, Seguridad Nacional, terrorismo, biocustodia.

\section{Intentional biological threats: Implications for National Security \\ SUMMARY}

The use of biological material as a weapon of war is as old as the war conflicts themselves, but after the signing, in 1972, of the Convention on the Prohibition of the Development, Production and Stockpiling of Bacteriological (Biological) and Toxin Weapons and on their Destruction (CABT), its military use has practically disappeared. However, it has become part of the attacks of terrorist groups, which constitute a real threat to National Security. Biological weapons are included within the group of so-called "weapons of mass destruction" and include all types of agents, microbial or not, viral, natural or recombinant, and their derived toxins. Among the key factors in the development of this type of intentional biological threats, it is worth mentioning the increase in the appearance of emerging pathogens, the great development of genetic modification and editing technologies, such as CRISPR/Cas9, or the diversion and smuggling of sensitive precursors and materials. To this end, the following measures have been implemented: launch of the National Biosecurity Commission; control of dual-use material exports; strengthening of the Security and Protection Area of the Customs and Special Taxes Department of the Tax Agency; development of the Network of Biological Alert Laboratories (RE-LAB), coordinated by the Carlos III Health Institute; collaboration of the Spanish Technical Assistance and Emergency Response Teams (START).

KEY WORDS: Biological threats, biological weapons, viruses, National Security, terrorism, biosecurity.

$\overline{\text { 1. Profesor Titular de Farmacología, Vicerrector de Investigación y Ciencia, Universi- }}$ dad Camilo José Cela, Madrid.

2. Teniente General de la Guardia Civil, Director Adjunto Operativo, Dirección General de la Guardia Civil, Madrid.

3. Consejera Técnica, Unidad de Investigación y Gestión del Conocimiento, Consejo de Seguridad Nuclear, Madrid.

4. Vicealmirante, Segundo Comandante y Jefe de Estado Mayor del Mando de Operaciones, Estado Mayor de la Defensa, Madrid.

5. Vocal Asesora, Gabinete Técnico de la Subsecretaría de Ciencia e Innovación, Ministerio de Ciencia e Innovación, Madrid.

6. Responsable Federal, Sindicato de Policía, FeSP-UGT, Madrid.

7. Senador, Secretario Primero de la Comisión de Defensa del Senado, Madrid.

Dirección para correspondencia: Prof. Francisco López-Muñoz, Universidad Camilo José Cela, C/ Castillo de Alarcón, 49, Urb. Villafranca del Castillo, 28692 Villanueva de la Cañada, Madrid.

*Este informe constituye parte del trabajo fin de curso presentado por los autores en el XLIII Curso de Defensa Nacional del CESEDEN (noviembre de 2020).

Recibido: 04 de marzo de 2021

Aceptado: 04 de junio de 2021

doi: $10.4321 /$ S1887-85712021000200006

\section{ANTECEDENTES HISTÓRICOS}

El empleo de material biológico como herramienta bélica hunde sus raíces en los primeros conflictos armados de los que se tiene constancia a lo largo de la historia de la Humanidad ${ }^{(1)}$, dada su capacidad para causar bajas masivas en el enemigo, al ser infectadas multitud de personas por contacto directo o indirecto con los agentes patógenos. Baste recordar, en este sentido, como el general cartaginés Aníbal, en la batalla de Eurymedon, en el año 190 a.C., mandó lanzar a la flota enemiga ollas de barro con serpientes venenosas en su interior.

Del mismo modo, en la Edad Media fue habitual, durante los asedios de las ciudades enemigas, el lanzamiento de cuerpos humanos o de animales en avanzado estado de putrefac-

\footnotetext{
(1) Puede consultarse Miller et al. (2002), Guillemin (2005), Szinicz (2005), Pita (2011).
} 
ción, como en el caso del asedio al castillo de Thyne Levesque (1340), en el norte de Francia, por parte del duque de Normandía durante la Guerra de los Cien Años. Otro ejemplo, fue el asedio de la ciudad de Caffa (Ucrania), en manos de los tártaros en 1346, por parte de los mongoles, quienes lanzaron con fines bélicos cuerpos de cadáveres infectados de la peste.

En fechas más recientes, durante la colonización de Norteamérica por las tropas británicas, trascendió la información de la distribución a diferentes tribus indias, en 1763, de mantas contaminadas de viruela, procedentes de un hospital donde eran tratados estos enfermos europeos, por parte de los soldados de Fort Pitt.

Pero donde alcanzó un mayor auge la guerra biológica (además de la química) fue durante las dos Guerras Mundiales del siglo XX. En la Primera, consta la creación de unidades alemanas dedicadas a infectar a los animales de carga de los aliados con las bacterias responsables del muermo (Burkbolderia mallei) y del carbunco (Bacillus anthracis). Para ello, aplicaban directamente sobre los animales un líquido que contenía las bacterias, o bien les administraban azúcar en forma de terrones con los patógenos encapsulados en su interior en minúsculos recipientes de vidrio. Tras el conocimiento de estos hechos, y de la existencia de un programa de armamento biológico alemán, al finalizar el conflicto armado algunos países europeos comenzaron a diseñar sus propios programas de guerra biológica, como Francia, en 1922, la Unión Soviética, en 1925, o Italia, en 1932.

El 17 de junio de 1925 se firmó el Protocolo de Ginebra, que entró en vigor el 8 de febrero de 1928. Este Protocolo prohibió el uso de armas biológicas (además de los gases asfixiantes), pero no prohibió su producción y almacenamiento, por lo que, aunque su entrada en vigor supuso el final de muchos programas de armamento biológico, algunos países continuaron con ellos.

De hecho, durante la Segunda Guerra Mundial siguieron usándose las armas biológicas; se lanzaron bombas de porcelana que contenían pulgas transmisoras de la peste, así como bombas de acero que liberaban esporas de Bacillus anthracis, aunque los efectos fueron prácticamente nulos. Pero mientras que Alemania no profundizó demasiado en este tipo de ataques, su aliado, Japón, puso en marcha en sus conflictos bélicos asiáticos auténticas campañas de guerra biológica, que comenzaron bastante antes del inicio de la Guerra, tras la toma de Manchuria por el Ejercito Imperial Japonés. Se ha estimado que, en el marco de los experimentos japoneses con armas biológicas, murieron unos 400.000 chinos $^{(2)}$.

\footnotetext{
(2) En este territorio de la actual República Popular China, el Teniente General Shiro Ishii organizó la célebre y tenebrosa Unidad 731 (y sus unidades satélites). Este microbiólogo comenzó en 1932 sus experimentos preliminares sobre guerra biológica en las zonas ocupadas de China como parte de un proyecto secreto para el Ejército Imperial. A título de ejemplo, en 1936 creó en Pingfang, a unos $20 \mathrm{~km}$ de Harbin (China), un gran complejo de investigación en el que se probaron varios tipos de bombas y se cultivaron pulgas para la transmisión de diferentes enfermedades, llegando a producir mensualmente $600 \mathrm{Kg}$ de ántrax y $1000 \mathrm{Kg}$ de bacilos del cólera. En Anda, zona de pruebas al aire libre ubicada a $120 \mathrm{~km}$ de la instalación de Pingfang, se realizaron experimentos a cielo abierto para determinar cuáles eran los sistemas más idóneos para la diseminación de epidemias, y en Changchun, la Unidad de Protección Equina Antiepizoótica (Escuadrón 100) infectaba animales con ántrax y peste y luego los liberaban en diferentes direcciones a lo largo de las tropas enemigas para producir epidemias. Estas acciones se focalizaban hacía el ejército chino, uni-
}

Tras este conflicto armado, el empleo de armas biológicas decayó drásticamente, hasta que, finalmente, el 10 de abril de 1972 se firmó la Convención sobre la prohibición del desarro1lo, la producción y el almacenamiento de armas bacteriológicas (biológicas) y toxínicas y sobre su destrucción, conocida con el acrónimo CABT. Gracias a este tratado, el empleo de armas biológicas en conflictos bélicos prácticamente ha desaparecido, pero en los últimos 40 años ha pasado a formar parte de los ataques de grupos terroristas, que constituyen una auténtica amenaza para la seguridad nacional de los diferentes países.

En 1984, la secta hinduista Rajneeshes, seguidores de Bhadwan Shree Rajneesh, envenenó con salmonela la comida en varios restaurantes de la localidad estadounidense de The Dalles (Oregón). Aunque no hubo fallecidos, se contabilizaron 751 afectados por la infección.

En 1990, la secta japonesa Aum Shinrikyo (La Verdad Suprema) realizó una diseminación de Bacillus anthracis en forma de suspensión líquida desde un edificio en Kameido (Tokio). Sin embargo, la cepa utilizada carecía de agresividad patogénica. Hasta 1995, el grupo realizó diversos ataques con toxina botulínica y agentes de carbunco líquido en diversos lugares, como el centro de Tokio, el metro, el aeropuerto, el Parlamento, e incluso en dos bases navales americanas, aunque no hubo ningún informe oficial de fallecidos o afectados.

Finalmente, el 18 de septiembre de 2001, tras el atentado de Nueva York contra las Torres Gemelas, se remitieron varios envíos postales que contenían esporas de Bacillus anthracis (hasta noviembre de ese año) a congresistas y a redacciones de diferentes medios de comunicación de EE.UU. El 5 de octubre falleció la primera persona por inhalación de estas esporas bacterianas, y posteriormente otras 4 más por esta misma vía. En total, hubo 22 casos de contaminación, 11 de ellos por inhalación y los otros 11 por contacto cutáneo. Afortunadamente, los efectos de este ataque bioterrorista fueron bastante limitados, debido a la adecuada profilaxis, así como al aislamiento y descontaminación, tanto de las instalaciones, como de las personas afectadas. Sin embargo, el impacto mediático y social fue enorme. Dichos envíos postales iban acompañados de unas notas con las expresiones "Muerte a América. Muerte a Israel. Alá es grande”, lo que en un principio hizo sospechar de Al Qaeda, si bien, en 2008 fue detenido por estos ataques el doctor Bruce E. Ivins del USAMRIID (United States Army Medical Research Institute of Infectious Diseases), pues la cepa de ántrax utilizada era idéntica a la existente en su centro de trabajo. Sin embargo, Ivins se suicidó y el caso no pudo ser definitivamente aclarado.

Para la lucha contra estos ataques terroristas, el Consejo de Seguridad de Naciones Unidas promulgó, en 2004, la resolución 1540 , que obliga a todos los países miembros de la ONU a

dades soviéticas de la frontera y sobre todo a la población cercana a los centros de experimentación, diseminando los gérmenes mediante ropas, comidas o bebidas contaminadas, o pulgas infectadas. Se investigó también sobre la mejor forma de diseminar los patógenos mediante sistemas de artillería, por ejemplo, para extender el ántrax, pero se comprobó que sólo unas pocas esporas sobrevivían a las explosiones. En ocasiones se diseminaban las bacterias creando una especie de nube contaminada tipo aerosol. Para ampliar información sobre los experimentos biológicos del Ejercito Imperial Japonés durante la guerra Sino-Japonesa, puede consultarse López-Muñoz et al. (2016). 
adoptar las medidas necesarias (incluyendo la adopción y modificación legislativa oportuna) para la fabricación, adquisición, posesión, desarrollo, transferencia o uso de armas biológicas y sus vectores (además de armas nucleares y químicas) por parte de sujetos vinculados a grupos terroristas. Esta resolución también obliga a la adopción de medidas para la prevención del tráfico ilícito de armas de destrucción masiva, así como de los materiales y tecnologías conexos, asegurando su inventariado y protección física.

\section{LAS ARMAS BIOLÓGICAS DENTRO DEL CONCEPTO DE "ARMAS DE DESTRUCCIÓN MASIVA"}

El concepto de "armas de destrucción masiva", ADM (del inglés weapons of mass destruction) hace referencia a aquellas que, de forma indiscriminada, son capaces de acabar con una elevada cantidad de personas y ocasionar daños medioambientales y económicos de gran envergadura. Dentro de ellas se incluyen las de tipo nuclear, químico y biológico, como se desprende de la Resolución 687 de Naciones Unidas de 1991, en la que se cita la "amenaza que todas las armas de destrucción masiva suponen para la paz y seguridad".

Se entiende como arma biológica aquella que emplea agentes biológicos, fundamentalmente patógenos, como herramienta bélica o con fines terroristas. Los agentes biológicos incluyen a todo tipo de agentes de naturaleza biológica, microbianos o no, naturales o recombinantes, y a los productos de naturaleza tóxica que se deriven de ellos (toxinas), y que tengan efectos lesivos, incapacitantes o letales sobre los seres humanos, los animales o las plantas. Además de bacterias y virus, pueden considerarse como agentes biológicos algunos seres de naturaleza eucariota, como hongos y parásitos, y otros organismos causantes de plagas, como moscas, mosquitos o escarabajos, siempre que se empleen como vectores de agentes biológicos, contribuyendo a la diseminación de los mismos. En el caso de los microorganismos, éstos deben reunir una serie de propiedades para poder ser utilizados como armas biológicas, como poseer una naturaleza patógena y elevada infectividad, facilidad de transmisión, periodos de incubación cortos, tasas de morbi-mortalidad elevadas, e inexistencia de vacunas y tratamientos efectivos o escasez de las mismos.

Las armas biológicas están integradas por un dispositivo de dispersión, que puede ser mecánico o un vector vivo, como ratas o insectos, y el agente biológico (microorganismos o sus toxinas), y pueden ser capaces de generar enfermedades en humanos, animales o plantas, o contaminar los suministros de alimentos, fuentes de agua, etc.

Existen tres métodos de diseminación de los agentes biológicos: mediante aerosoles, que facilitan la penetración del agente a través del aparato respiratorio; mediante el sabotaje ambiental del agua, el aire, etc.; y mediante vectores, como mosquitos, moscas, piojos, garrapatas, etc., que alcanzan a humanos, animales y plantas. Esta última forma, aunque históricamente importante, es hoy en día inusual por su peligrosidad, al ser imprevisible e incontrolable. Un hipotético método de diseminación, en el ámbito de los ataques terroristas, podría ser el uso de portadores humanos, conocedores o no del hecho, para diseminar la enfer- medad en lugares de gran aglomeración de personas, como aeropuertos y otras infraestructuras de transporte.

En la actualidad, el empleo bélico de las armas biológicas parece muy improbable, por las regulaciones internacionales y la naturaleza intrínseca cruel de las mismas, cuyas consecuencias serían mostradas en directo en este mundo global, siendo los ataques bioterroristas bastante más factibles, precisamente por el impacto en los medios de sus efectos devastadores.

\section{ORIGEN DE LA AMENAZA: TERRORISMO O CONFLICTO BÉLICO}

Si bien la amenaza de las armas biológicas se afrontó, en un principio, desde la perspectiva de su potencial bélico para el desarrollo de ADMs por parte de actores estatales, circunscribiéndose por tanto a ámbitos exclusivamente militares, en la actualidad no se entiende el afrontar una amenaza como ésta sin tener altamente presente el riesgo que supone su uso por actores no estatales con fines terroristas.

De hecho, el efecto más pernicioso y temido de un ataque con agentes biológicos no sólo se limita al daño físico para las personas (aunque también puede afectar a los animales y los cultivos) que puede causar una toxina, un virus o una bacteria, sino también los daños psicológicos que, multiplicados por su efecto mediático, generaría en la población una sensación de terror y pánico, que son precisamente algunos de los objetivos perseguidos por las organizaciones terroristas a la hora de llevar a cabo sus acciones.

Hasta el momento, únicamente ha sido catalogada como acción terrorista utilizando un agente biológico la comentada del año 2001 en EE.UU., aunque previamente también hubo intentos en Japón por parte de la secta Aum Shinrikyo. Es por ello que no hay que subestimar el uso de agentes biológicos con fines terroristas, máxime cuando, en los últimos años, los instigadores de la Yihad reclaman de sus seguidores la perpetración de atentados en Occidente mediante el uso de sustancias químicas o biológicas, con el fin de generar terror de forma indiscriminada.

No obstante, la comisión de un ataque terrorista en Europa utilizando agentes biológicos se considera "poco probable", debido principalmente a los siguientes factores:

- Necesidad de contar con unas instalaciones mínimamente equipadas para el desarrollo y reproducción del agente biológico.

- Disponibilidad de expertos con conocimientos técnicos adecuados.

- Necesidad de un medio de dispersión adecuado.

- Respaldo financiero por parte de la organización.

- Riesgo para los propios terroristas derivado de la manipulación negligente del agente biológico que haga que éste se vuelva en contra de quienes pretenden usarlo.

- Un ataque convencional (por ejemplo, con un artefacto explosivo improvisado) sería igual o más efectivo, con menos complicaciones.

Todos estos retos impiden, por el momento, que grupos terroristas como DAESH o Al-Qaeda, o actores solitarios inspi- 
rados en los mismos, dispongan de la capacidad necesaria para atentar con agentes biológicos.

\section{RELEVANCIA ACTUAL DE LA AMENAZA BIOLÓGICA PARA LA SEGURIDAD NACIONAL}

Como se ha mencionado previamente, el uso de armas químicas y biológicas podría constituir una grave amenaza para la seguridad nacional, principalmente por su capacidad de desestabilización, provocando un colapso en la población, crisis económica, incluso pudiendo alcanzar objetivos estratégicos y operacionales. A continuación, se describen los tres factores claves en el desarrollo de este tipo de amenazas biológicas intencionadas.

\section{Incremento de la aparición de patógenos emergentes}

La Organización Mundial de la Salud (OMS) establece que la infección de un grupo de personas constituye una epidemia, pero al aumentar progresivamente el número de casos afectados se convierte en una pandemia, pudiendo alcanzar una extensión masiva, en otros continentes y hemisferios.

Señala la OMS que las infecciones respiratorias, enfermedades diarreicas, tuberculosis, sida (VIH), malaria y sarampión se han situado, en solo quince años, entre las veinte primeras causas de muerte en el mundo. Esto podría explicar la importancia de los agentes infecciosos como amenaza biológica, destacando entre ellos los agentes virales, motivo por el cual la investigación, el estudio y el conocimiento de los mismos se ha incrementado muy ampliamente en las últimas décadas.

Los virus son microorganismos infecciosos muy sencillos, pues solo contienen en su interior material genético (ARN o ADN), rodeado por una cubierta constituida por determinadas proteínas, que ayudan a que su material genético penetre en otra célula, ya que los propios virus no son capaces de reproducirse por sí mismos. Por ello necesitan una célula huésped a la que infectan y, tras introducirse en ella, la utilizan para replicar copias de sí mismos y multiplicarse. Una vez conseguido, pueden destruir la membrana de esa célula y trasladarse a otras, repitiendo de forma exponencial el proceso de infección. Existen diferentes familias de virus con potencialidad de generar una amenaza biológica.

Los coronavirus constituyen una familia vírica que afecta tanto al ser humano como a los animales (i.e., aves y mamíferos), teniendo capacidad de transmitirse entre especies. Además de la actual pandemia de la Covid-19 por el coronavirus $S A R S$ CoV-2, los más comunes hasta ahora han sido:

- Virus influenza A (H1N1). A mediados de 2009, la OMS declaró la situación de pandemia debida a un virus nuevo H1N1 de origen porcino, que, en el mes de marzo de ese año, comenzó a producir numerosos casos de gripe en México, y se extendió por todo el mundo. Su transmisibilidad fue superior a la de la gripe estacional, y dada su agresividad, contagio y virulencia, los dos hemisferios se vieron afectados, siendo los grupos más sensibles los niños, jóvenes y adultos menores de 30 años, y concentrándose la mortalidad en las personas de 20 a 50 años.
- SARS-CoV. Este virus ocasiona el síndrome respiratorio agudo grave (Severe Acute Respiratory Syndrome, SARS). La primera vez que se tuvo conocimiento sobre el SARS fue en Asia, en febrero de 2003. Rápidamente, en pocos meses, la enfermedad se propagó a más de 25 países de Norteamérica, Suramérica, Europa y Asia, antes de que esta epidemia pudiera ser controlada.

- MERS-CoV. Este coronavirus ocasionó el síndrome respiratorio de Oriente Medio (MERS), también denominado como EMC/2012 (HCoV-EMC/2012), una enfermedad respiratoria vírica identificada por primera vez en Arabia Saudita en 2012, extendiéndose por varios países de Oriente, como Egipto, Omán o Qatar. Los datos científicos indican que las personas se infectan por contacto directo (de persona a persona) o indirecto, posiblemente a través de dromedarios, aunque no se descartan otros reservorios animales. Por el momento no hay vacunas ni tratamientos específicos para el MERS, salvo terapias de apoyo.

Otra familia de virus muy peligrosos son los filovirus (Filoviridae, de la clase $\mathrm{V}$, según la clasificación de Baltimore) ${ }^{(3)}$, entre los que se encuentran los virus de Marburg y Ébola, aunque tienen características serológicas, bioquímicas y genéticas distintas. Se conocen tres subtipos del virus del Ébola (Zaire, Sudán y Costa de Marfil), que comparten algunos epítopos iguales. $\mathrm{Su}$ transmisión tiene lugar por contacto directo con líquidos corporales infectados, como la sangre, la saliva, el sudor, la orina o los vómitos, de animales o humanos, vivos o fallecidos. Causan fiebres hemorrágicas graves o mortales, caracterizadas por anormalidades en el sangrado y en la coagulación sanguínea, incluyendo el sangrado difuso. Su incidencia es endémica en África. El virus del Ébola destruye el sistema inmunitario, atacando a las células del sistema inmunológico, que intenta protegerse generando anticuerpos. No existe tratamiento específico para estos virus. Sin embargo, en 2019 fue autorizada la primera vacuna contra el virus del Ébola-Zaire por la Agencia Europea de Medicamentos (EMA) y la Administración de Alimentos y Medicamentos de los Estados Unidos (FDA), e, inmediatamente, precalificada por la OMS, lo que supone que cumple las normas de calidad, seguridad y eficacia de la esta Organización. La vacuna ya ha sido aplicada en varias epidemias en la República Democrática del Congo y los datos confirman su eficacia en la protección de personas con riesgo y en la reducción de la transmisión del virus. Y más recientemente, en enero de 2021, se ha creado la primera reserva mundial de la vacuna, que se almacenará en Suiza.

Los arbovirus, transmitidos por artrópodos, son virus que pasan al ser humano o a otros vertebrados mediante ciertas especies de artrópodos hematófagos, especialmente insectos (moscas y mosquitos) y arácnidos (garrapatas). Entre las patologías que pueden ocasionar, destacan:

- La enfermedad de Chikungunya, que se transmite por los mosquitos Aedes y es más frecuente en África, India,

\footnotetext{
(3) Los filovirus son partículas pleomórficas que aparecen como hebras filamentosas, algunas veces con ramas, en forma de $\mathrm{U}$ o configuraciones circulares. Su estructura es filamentosa, muy grande ( $80 \mathrm{~nm}$ de diámetro y hasta $14.000 \mathrm{~nm}$ de longitud), con cápsides helicoidales y está rodeado de una envoltura. Posee una hebra de ácido ribonucleico monocatenario sentido negativo y se replica en el citoplasma celular.
} 
Pakistán, Guam, el Sudeste Asiático, Nueva Guinea, China, México, América Central y del Sur, islas del Caribe, el Océano Índico y áreas específicas de Europa. Esta enfermedad ocasiona un cuadro clínico febril agudo, seguido de una poliartritis crónica que puede continuar durante meses o años.

- Enfermedad de Mayaro, semejante al dengue, y que es transmitida por mosquitos. Es más frecuente en Brasil, Bolivia y Trinidad.

- La fiebre de Oropouche, ocasionada por el virus de Oropouche (OROV), un bunyavirus del grupo Simbu. El OROV se transmite a los seres humanos a través del Culicoides paraensis, una especie de mosquitos picadores presentes en América del Sur, Central y el Caribe. No existe una vacuna contra esta infección y puede conducir a meningitis y meningoencefalitis.

- La fiebre amarilla es una enfermedad vírica aguda, hemorrágica, transmitida por mosquitos infectados. El virus es endémico en las zonas tropicales de África y América Latina. No hay tratamiento curativo para la fiebre amari1la. La vacunación, segura, asequible y eficaz, es la medida preventiva más importante contra la fiebre amarilla.

Los flavivirus, de los cuales existen tres variantes, europeo, siberiano y del Lejano Oriente, causan encefalitis. Esta enfermedad es transmitida por la picadura de garrapatas, concretamente por Ixodes ricinus en Europa e Ixodes persulcatus en Siberia y el Lejano Oriente. Es importante conocer que las garrapatas son reservorios de vectores y virus, y los roedores pequeños son el principal huésped amplificador. Otra encefalitis por garrapatas es causada por el virus Powassan (POWV), un flavivirus que está relacionado antigénicamente con el virus del Nilo Occidental y la encefalitis de St. Louis. Tampoco hay vacuna para esta infección por POWV.

\section{Gran desarrollo de las tecnologías de modificación y edición genética}

Actualmente, la edición genética es una técnica que permite modificar, añadir o eliminar segmentos de ADN para cambiar de forma precisa su secuencia, alterando así las características de un determinado organismo. Entre estas tecnologías, destaca la CRISPR/Cas9, que es una herramienta molecular utilizada para editar o corregir el genoma de cualquier célula. Los CRISPR son familias de secuencias de ADN bacterianos (repeticiones palindrómicas cortas agrupadas y regularmente interespaciadas en bacterias; en inglés, clustered regularly interspaced short palindromic repeats) ${ }^{(4)}$.

Posteriormente, los científicos han utilizado la herramienta CRISPR fuera de las bacterias para cortar y pegar trozos de material genético en cualquier célula. De este modo, la tecno-

\footnotetext{
(4) El origen de esta tecnología CRISPR/Cas9, descubierta y desarrollada por Francisco Martínez Mojica, se encuentra en el sistema de defensa inmunitario de las bacterias ante los virus. Para ello, las bacterias cuentan con una proteína, llamada Cas9, que, junto con un ARN guía (gARN), permite identificar, cortar y destruir la secuencia del ADN vírico. La Cas9 es una nucleasa, una enzima especializada en cortar ADN, con dos sitios de corte activos (HNH y RuvC), uno para cada hebra de la doble hélice.
}

logía CRISPR-Cas9 puede ofrecer la capacidad de modificar o corregir directamente los cambios asociados a una determinada enfermedad subyacente en el genoma, y proporcionar un gran potencial en medicina, alimentación, agricultura o medio ambiente. El poder de estas tijeras moleculares es inmenso, por lo que fue considerado el mayor avance científico del año 2015. Y precisamente por ello, se debería controlar su utilización.

Algunos ejemplos pueden ilustrar este punto. El Centro para Control y Prevención de Enfermedades (CDC) reconstruyó, en 2005, el virus de la gripe $H 1 N 1$, que ocasionó la mal llamada "gripe española" de 1918. El objeto de identificar la secuencia del genoma de este virus fue estudiar las propiedades que lo hicieron tan agresivo y analizar, con las herramientas y medios actuales, como hacer frente a un virus de estas características. Sin embargo, en la investigación y reconstrucción de los ocho segmentos genéticos del citado virus afloraron numerosos interrogantes relativos a la bioseguridad. Este argumento está basado en que la genética inversa (que es la técnica posiblemente utilizada para reconstruir el virus) se encuentra hoy en día al alcance de un gran número de laboratorios de varios países. Otro ejemplo que tuvo lugar en 2018 , fue la reconstrucción del virus de la viruela equina, enfermedad declarada como erradicada por la OMS en 1980. Todo esto pone de manifiesto el riesgo del uso de estas tecnologías con fines ilícitos.

\section{Desvío y contrabando de precursores y materiales sensibles}

La Resolución 1540 del Consejo de Seguridad de Naciones Unidas (CSNU) insta a los Estados a establecer las medidas apropiadas para evitar y prevenir la proliferación de agentes biológicos por actores no estatales. Para ello se requiere el diseño de un régimen de biocustodia a nivel estatal que evite el desvío y contrabando de materiales sensibles, cuyo objetivo global es la protección de las personas, propiedades e instalaciones, del medio ambiente y de la sociedad en su conjunto, de actos ilícitos. Es decir, el objetivo es minimizar que se puedan producir brotes biológicos inusuales, tanto de forma accidental, como de forma intencionada. Para ello, se deben tomar acciones de protección contra la sustracción y el sabotaje de agentes y materiales biológicos relevantes en las correspondientes instalaciones que los albergan, asegurando la puesta en práctica de medidas rápidas, efectivas y exhaustivas que permitan la protección necesitada. Todo ello debe estar integrado y coordinado dentro de un Plan Nacional de Biocustodia.

\section{RETOS Y DESAFÍOS: DETECCIÓN PRECOZ E IDENTIFICACIÓN DE AMENAZAS}

Como se ha mencionado previamente, se considera "poco probable" la comisión de un ataque terrorista en Europa utilizando agentes biológicos. No obstante, para mantener esta baja probabilidad hay que tener identificados los riesgos y establecidos los elementos de prevención; y en caso de que el ataque se produzca, dar la adecuada respuesta que reduzca sus efectos.

Las medidas preventivas se basan en el control de los patógenos y la inteligencia sobre la capacidad de acceso a ellos que tienen 
los terroristas. Entre ellas se encuentra el Plan de Biocustodia, el control de comercio exterior, que incluye como instrumentos, entre otros, la seguridad de aduanas, así como los controles de inmigración y de los movimientos transfronterizos de residuos peligrosos.

Las medidas de respuesta o defensa asientan su eficacia en la rapidez con que se puedan implantar. El tiempo es, por tanto, un factor clave para reducir la transmisión del agente biológico y, por tanto, sus efectos sobre la población. Para ello es necesario disponer de un sistema que permita la detección del ataque e identificar el patógeno concreto. Entre las herramientas de respuesta está la Red de Laboratorios de Alerta Biológica y los equipos sanitarios y de descontaminación, ya sean civiles o militares.

\section{Puesta en marcha de la Comisión Nacional de Biocustodia}

El Plan Nacional de Biocustodia, aprobado en 2019, busca desarrollar todas las medidas necesarias para posibilitar la elaboración de un inventario de agentes biológicos relevantes a nivel nacional; la custodia efectiva de esos agentes, controlando el acceso físico a ellos; la protección física de las instalaciones donde se manejen dichos agentes; y el control del transporte y la transferencia de esos agentes dentro del territorio nacional.

El Plan incluye la creación de la Comisión Nacional de Biocustodia que se encargue de hacer el seguimiento del plan. En ella está representada la Presidencia del Gobierno y hasta 13 Ministerios, lo que pone de manifiesto que para hacer frente a la amenaza biológica es imprescindible una aproximación multidisciplinar. La Comisión, de reciente creación, debería aprovechar la mentalización actual, consecuencia de la Covid-19, para impulsar su trabajo.

\section{Implementación de herramientas para controlar las exportaciones de material de doble uso}

Además del Plan de Biocustodia, es necesario controlar el comercio que de este material se pueda producir, y la herramienta para hacerlo es la legislación existente para el control del comercio exterior de material de doble uso, donde están incluidos los agentes biológicos, de acuerdo con las definiciones que de ellos se hace en la Ley Orgánica 12/1995 de Represión de Contrabando.

La regulación del comercio se recoge en la Ley 53/2007, de 28 de diciembre, sobre control del comercio exterior de material de defensa y de doble uso, y su desarrollo en el Real Decreto 679/2014, de 1 de agosto, por el que se aprueba el Reglamento de control del comercio exterior de material de defensa, de otro material y de productos y tecnologías de doble uso. Este reglamento incluye, además de la determinación de las condiciones, requisitos y procedimientos para el control de ese comercio, los anexos detallados de esos materiales, entre los que se cuenta el material susceptible de ser empleado para el desarrollo de armas bacteriológicas (biológicas) y tóxicas. El instrumento para hacer cumplir el citado Reglamento es la Junta Interministerial para el Comercio y Control del Material de Defensa y Tecnologías de Doble Uso (JIMDDU), la cual realiza el control y seguimiento de las autorizaciones para la exportación.
Existen suficientes mecanismos legales que regulan el control de las exportaciones de tecnología de doble uso en el ámbito biológico, así como los organismos para llevar a cabo ese control. El reto, como suele ocurrir habitualmente, es conseguir aplicar la normativa, dotando a los organismos de los medios materiales y humanos para hacerlo de forma eficaz.

\section{Papel del Área de Seguridad y Protección del Departamento de Aduanas e Impuestos Especiales de la Agencia Tributaria}

Para aquellos que intentan esquivar la legislación de Comercio mencionada, el Estado cuenta con el Área de Seguridad y Protección del Departamento de Aduanas e Impuestos Especiales de la Agencia Tributaria.

Los aspectos de seguridad en la legislación de aduanas de la U.E. se comenzaron a implantar a partir de 2005, como respuesta a los atentados de las Torres Gemelas de 2001. Se trataba de proteger a los ciudadanos europeos de los riegos derivados del comercio ilícito de materiales. Entre las medidas adoptadas se establece un sistema de información de control de las importaciones (ICS) y actualmente está en proceso de implantación el Programa de seguridad y protección de las aduanas de la UE antes de la llegada de las mercancías, respaldado por un sistema de información denominado ICS2.

E1 ICS2 se pondrá en funcionamiento entre 2021 y 2025 y sin duda mejorará la capacidad de las naciones para contribuir con mayor eficacia a la seguridad aduanera de la U.E. y por tanto fortalecerá la protección de los ciudadanos europeos frente a las amenazas, entre ellas la biológica ${ }^{(5)}$.

\section{Desarrollo de la Red de Laboratorios de Alerta Biológica (RE- LAB), coordinada por el Instituto de Salud Carlos III (ISCIII)}

A raíz de los sucesos que siguieron a los atentados terroristas del 2001 en EE.UU., a los que ya se ha aludido, se pusieron de manifiesto las deficiencias en la preparación, coordinación y respuesta rápida ante estos nuevos tipos de amenaza para la Salud Pública

La RE-LAB se crea en España en 2009, ante la falta de laboratorios de referencia con el nivel de seguridad biológica adecuado para detectar e identificar agentes altamente patógenos. Se regula por Orden del Ministerio de la Presidencia ${ }^{(6)}$ y su gestión y dirección científico-técnica corresponde al Ministerio de Ciencia e Innovación, a través del Instituto de Salud Carlos III.

Desde su creación en el año 2009 (formada por cinco laboratorios de referencia y dos laboratorios colaboradores), la RE-LAB se ha ido ampliando para alcanzar un mayor ámbito geográfico e incorporar laboratorios especializados en la mayo-

\footnotetext{
(5) https://www.agenciatributaria.es/AEAT.internet/Inicio/La_Agencia_Tributaria/Aduanas_e_Impuestos_Especiales/_Presentacion/Procedimientos_y_ gestiones_en_la_Aduana/_ICS2_/Informacion_sobre_el_ICS2/ Programa de seguridad y proteccion de las aduanas de la UE antes de_la_llegada_de_las_mercancias_Sistema_de_Control_de_Impor_Introduccion.shtml

(6) Orden PCI/1381/2018, de 18 de diciembre, por la que se regula la Red de Laboratorios de Alerta Biológica "Re-Lab".
} 
ría de las áreas de riesgo, hasta contar, en la actualidad, con 12 laboratorios de referencia, tanto de ámbito estatal como autonómico, y un laboratorio colaborador ${ }^{(7)}$. Recientemente se está explorando el interés de las unidades NBQ de los Mossos de Escuadra y de la Ertzaintza para incorporarse a la Red.

La RE-LAB se constituye como una estructura de investigación y de intercambio de información científico-técnica, que comparte recursos comunes, como son más de 250 técnicas de detección de un gran número de agentes biológicos y toxinas de alto riesgo y un repositorio de cepas y material de referencia a disposición de todos los miembros de la red. Asimismo, cuenta con un inventario de los patógenos de alto riesgo disponibles en cada laboratorio que integra la red y una plataforma "share point" para compartir de forma segura la información.

Esta Red es fundamental para paliar los riesgos que implicaría la liberación, ya sea intencionada o accidental, de agentes biológicos, y constituye un instrumento imprescindible en la coordinación y respuesta ante este tipo de amenazas.

\section{Colaboración de los Equipos Técnicos Españoles de Ayuda y Respuesta en Emergencias (START)}

La creación de los START, o "chalecos rojos", es un proyecto de la Oficina de Acción Humanitaria de la Agencia Española de Cooperación (AECID), integrado en el mecanismo de la Comisión Europea denominado "European Emergency Response Capability".

España dispone de un equipo con capacidad quirúrgica (EMT II) formado por 65 personas, entre sanitarios (43) y personal de logística (12), con su equipamiento para desplegar, en menos de 72 horas, un hospital de campaña en cualquier lugar del mundo. Este equipo se desplegó por primera vez en Mozambique, en noviembre de $2019^{(8)}$.

En el marco de los ejércitos, la Unidad Militar de Emergencias, la Agrupación de Sanidad del Ejército de Tierra y la Unidad Médica Aérea de Apoyo al Despliegue son unidades con capacidad de respuesta para hacer frente a este tipo de amenazas.

Estos equipos de respuesta ante emergencias no están orientados específicamente a la lucha contra ataques biológicos, pero podría ser una capacidad nacional a considerar en la respuesta nacional contra las amenazas biológicas.

\section{CONCLUSIONES}

En la actualidad, el empleo de armas biológicas como una posible amenaza para la seguridad nacional es más factible desde fuentes terroristas que procedente de un ataque bélico, dadas las amplias regulaciones internacionales existentes en estos momentos. Su uso con fines terroristas, aunque no fácil, podría ejercer efectos devastadores en la sociedad.

\footnotetext{
(7) Resolución de 29 de enero de 2019 del Secretario General de Política Científica, por la que se fija la composición de la Red de Laboratorios de Alerta Biológica(RE-LAB).

(8) https://www.dclm.es/noticias/92255/una-enfermera-ciudadrealena-en-el-spanish-technical-aid-response-team.
}

Estas amenazas biológicas, como agresiones transversales que afectan a distintos actores y estructuras del Estado, exigen una respuesta coordinada y conjunta, tanto a nivel nacional por parte de las diferentes administraciones públicas concernidas, incluyendo la cooperación entre el sector público y el privado, como a nivel internacional.

Toda vez que este tipo de amenaza está íntimamente relacionada con la proliferación de ADM (entre las que se incluyen las armas biológicas), a la hora de establecer este modelo integral de gestión de crisis sería conveniente apoyarse o realizarlo en el marco del Comité Especializado de No Proliferación, creado en el año 2018 (Orden PRA/29/2018) como órgano de apoyo al Consejo de Seguridad Nacional para el complimiento de las funciones asignadas al mismo, dentro del Sistema de Seguridad Nacional. Máxime teniendo en cuenta que entre sus funciones está la de "realizar, en apoyo del Comité Especializado de Situación, la valoración de los riesgos y amenazas, analizar los posibles escenarios de crisis, en especial de aquéllos susceptibles de derivar en una situación de interés para la Seguridad Nacional". De hecho, en el seno de dicho Comité, en el año 2019, se elaboró el Plan Nacional de Biocustodia aludido previamente, lo que refuerza aún más la conveniencia y coherencia de que un futuro modelo de gestión de crisis en este ámbito se realice en el marco del reiterado Comité, aprovechando así su experiencia en la materia y los mecanismos y protocolos de coordinación ya establecidos en su seno.

\section{BIBLIOGRAFÍA}

1. Campos JP. Premio Nobel de química para el método CRISPR-Cas9 de edición del genoma. Investigación y Ciencia, 7 octubre 2020. Disponible en: https://www.investigacionyciencia.es/noticias/premio-nobel-de-qumica-parael-mtodo-crispr-cas9-de-edicin-del-genoma-19099.

2. Cique Moya A. Retos y desafíos de la biología sintética. Instituto Español de Estudios Estratégicos. Documento Marco 35/2015. Disponible en: http:// www.ieee.es/Galerias/fichero/docs_marco/2015/DIEEEM35-2015_Biologia_ Sintetica_AlbertoCiqueMoya.pdf.

3. Delgado-Iribarren A, Fernández Rodríguez A, Jado García I, Ybarra de Villavicencio C. El laboratorio de Microbiología en respuesta al bioterrorismo. En: Fernández Rodríguez A, coord., y Cercenado Mansilla E, Cantón Moreno R, eds. Procedimientos en Microbiología Clínica. Sociedad Española de Enfermedades Infecciosas y Microbiología Clínica (SEIMC), 2020.

4. Dougherty J, Pfaltzgraff RL. Contending Theories of International Relations: A Comprehensive Survey. New York: HarperCollins Publishers, 1990.

5. G8 Sommet d'Evian. Partenariat Mondial du G8 contre la prolifération des Armes de Destruction Massive et des Matieres Connexes: Plan d'Action. Evian, 2 juin 2003. Paris: Ministère des Affaires Etrangères, 2003.

6. Guillemin J. Biological weapons. New York: Columbia University Press, 2005 .

7. Instituto Español de Estudios Estratégicos. Emergencias pandémicas en un mundo globalizado: Amenazas a la seguridad. Cuaderno de Estrategia 203; 2020. Disponible en: http://www.ieee.es/publicaciones-new/cuadernos-deestrategia/2020/Cuaderno_203.html.

8. López-Muñoz F, Cuerda Galindo E, González López E. Los centros de experimentación japoneses: 1933-1945. En: Cuerda E, López-Muñoz F, eds. Cuando la Medicina no cura. La participación del personal sanitario en torturas, genocidios y experimentos al margen de los códigos éticos. Madrid: Delta Publicaciones, 2016, pp. 97-130.

9. Miller J, Engelberg S, Broad W. Guerra Bacteriológica. Las armas biológicas y la amenaza terrorista. Barcelona: Ediciones B, 2002.

10. Pereira Hernández C. Bioterrorismo. Boletín de Información 2007; 298: 49-72. 


\section{Amenazas biológicas intencionadas: implicaciones para la Seguridad Nacional}

11. Pérez Mellado R, Escauriaza Leal R. Convención para la prohibición de las Armas Biológicas: una herramienta para la seguridad internacional. Ministerio de Asuntos Exteriores y de Cooperación, Gobierno de España. Disponible en: https://www.miteco.gob.es/es/calidad-y-evaluacion-ambiental/temas/ biotecnologia/Divulgacion\%20CABT_tcm30-190285.pdf,

12. Pita R. Armas Biológicas. Una historia de grandes engaños y errores. Madrid: Plaza y Valdés Editores, 2011.

13. Sánchez Angulo M. Microbiología forense y bioterrorismo: el caso Amerithrax. Revista Cultural Digital Ars Creatio 2020; 60. Disponible en: http:// www.arscreatio.com/revista/articulo.php?articulo $=477$,

14. Shields JM, Potter WC. Dismantling the Cold War: US and NIS Perspectives on the Nunn-Lugar Cooperative Threat Reduction Program. Cambridge (MASS): MIT Press, 1997.

15. Szinicz L. History of chemical and biological warfare agents. Toxicology 2005; 214 : 167-81.

16. Biological Threats to US National Security, United States Senate Committee on Armed Services Subcommittee on Emerging Threats and Capabilities Testimony of Tom Inglesby, MD Director, Center for Health Security Johns Hopkins Bloomberg School of Public Health. November 20, 2019.

17. Boletín Oficial del Estado A-2018-795. (s.f.). www.boe.es. Disponible en https://www.boe.es/diario_boe/txt.php?id=BOE-A-2018-795.

18. Boletín Oficial del Estado A-2019-2553. (s.f.). www.boe.es. Disponible en https://www.boe.es/diario_boe/txt.php?id=BOE-A-2019-2553.

19. Convención sobre "la prohibición del desarrollo, la producción, el almacenamiento y el empleo de armas químicas y sobre su destrucción" ratificada por España el 3 de agosto de 1994.

20. Departamento de Seguridad Nacional, Gabinete de Presidencia del Gobierno. Estrategia de Seguridad Nacional 2017.

21. Departamento de Seguridad Nacional, Gabinete de Presidencia del Gobierno. Informe Anual de Seguridad Nacional 2019.

22. Dirección General de Salud Pública, Calidad e Innovación, Ministerio de Sanidad, Servicios Sociales e Igualdad. Sistema de Alerta Precoz y Respuesta Rápida 2013.

23. Estrategia global para la política exterior y de seguridad de la Unión Europea.

24. Ley 49/1999, "sobre medidas de control de sustancias químicas susceptibles de desvió para la fabricación de armas químicas", de 30 de Diciembre de 2001.

25. Ley 53/2007 "Sobre el control del Comercio Exterior de material y Defensa y de doble uso" de 28 de Diciembre de 2007.

26. Ley Orgánica 12/1995 de 12 de diciembre sobre el control del comercio exterior del material de defensa y de doble uso.
27. Ley Orgánica 3/1992 de 30 de abril por la que se establecen los supuestos de contrabando en materia de exportación de material de defensa o material de doble uso.

28. Ministerio de Sanidad. Enfermedades infecciosas importadas por inmigrantes residentes en España que se desplazan temporalmente a sus países de origen (VFRs). Disponible en: https://www.mscbs.gob.es/profesionales/saludPublica/prevPromocion/promocion/migracion/migracion.htm\#paisesOrigen.

29. Ministerio de Sanidad. Estrategias básicas de abordaje de las enfermedades infecciosas en inmigrantes, viajeros, e inmigrantes viajeros. Disponible en: https://www.mscbs.gob.es/profesionales/saludPublica/prevPromocion/promocion/migracion/migracion.htm\#estrategias.

30. Ministerio de Sanidad. Estudio de inmigración y Salud Pública. Disponible en: https://www.mscbs.gob.es/profesionales/saludPublica/prevPromocion/ promocion/migracion/migracion.htm\#estudio.

31. Oficina de Asuntos de Desarme de las Naciones Unidas. (s.f.). www.un.org. Disponible en: https://www.un.org/disarmament/es/adm/armas-biologicas/.

32. Orden de 27 de julio de 1998 por la que se desarrolla la estructura del Departamento de Aduanas e Impuestos Especiales de la Agencia Estatal de Administración Tributaria.

33. Orden ECC/1493/2016, de 19 de septiembre, por la que se actualizan los anexos del Reglamento de control del comercio exterior de material de defensa, de otro material y de productos y tecnologías de doble uso, aprobado por el Real Decreto 679/2014, de 1 de agosto.

34. Orden ICT/657/2018, de 13 de junio, por la que se modifican los anexos del Reglamento de control del comercio exterior de material de defensa, de otro material y de productos y tecnologías de doble uso, aprobado por el Real Decreto 679/2014, de 1 de agosto.

35. Protocolo de Ginebra de 1925, por el que se prohíbe el empleo, en la guerra, de armas biológicas (bacteriológicas).

36. Real Decreto $1782 / 2004$, de 30 de Julio, por el que se aprueba el Reglamento de control del comercio exterior de material de defensa, de otro material y de productos y tecnologías de doble uso.

37. Real Decreto $480 / 1988$ de 25 Marzo por el que se determinan las atribuciones, cometidos y funcionamiento de la Junta Interministerial Reguladora del Comercio Exterior de Material de Defensa y Productos de Tecnologías de Doble Uso.

38. Real Decreto 824/1992 por el que se aprueba Reglamento de Comercio Exterior de Material de Defensa y de Material de Doble Uso.

39. Resolución de Naciones Unidas-1540 (2004), aprobada por el Consejo de Seguridad en su $4956^{\mathrm{a}}$ sesión, celebrada el 28 de abril de 2004 